\title{
Vaginal paraurethral leiomyoma
}

\author{
Smita Anand Bijwe ${ }^{1 *}$, Anil T. Deshmukh ${ }^{2}$, Srishti Tanya ${ }^{1}$
}

\author{
${ }^{1}$ Department of Obstetrics \& Gynaecology, Dr. PDM Medical College, Amravati, Maharashtra, India \\ ${ }^{2}$ Department of Pathology, Dr. PDM Medical College, Amravati, Maharashtra, India
}

Received: 11 August 2014

Accepted: 19 August 2014

\section{*Correspondence:}

Dr. Smita Anand Bijwe,

E-mail: dranandbijwe@gmail.com

(C) 2014 Bijwe SA et al. This is an open-access article distributed under the terms of the Creative Commons Attribution Non-Commercial License, which permits unrestricted non-commercial use, distribution, and reproduction in any medium, provided the original work is properly cited.

\begin{abstract}
Leiomyomas of the vagina are uncommon soft tissue tumors. Only a few cases are reported in medical literature. It is usually seen between 20-80 years of age. We report a case of 30-year-old woman with paraurethral leiomyoma. Leiomyomas in this location should be differentiated from urethral diverticula and vaginal cysts. Complete surgical excision should be the choice of treatment. Excision usually has good prognosis and rarely recurs.
\end{abstract}

Keywords: Leiomyoma, Vagina, Paraurethral, Surgery

\section{INTRODUCTION}

Leiomyomas develop most commonly in the uterine corpus and much less often in the cervix. They may develop in round ligament but this is rare. Growth of leiomyomas is dependent on estrogen production. Tumor thrives during years of highest ovarian activity. Leiomyomas are common tumours of mesenchymal origin, well-circumscribed and can develop where smooth muscle is present. ${ }^{1}$ Leiomyoma outside uterus has been reported in various sites such as vulva, perineum and buccal mucosa. ${ }^{2}$ There are few reports of leiomyomas arising from paraurethral region. ${ }^{3}$ There can be diagnostic difficulty and hence we are presenting this case.

\section{CASE REPORT}

A 30 year old married woman, gravid two presented to out-patient clinic with complains of small swelling over vulva since 3 years. Since 15 days she noticed sudden increase in size causing discomfort. There was no history of urinary complain, sexually transmitted disease, fever or trauma. General examination revealed a healthy woman. On local examination there was $6 \times 7 \mathrm{~cm}$ mass arising from anterior vaginal wall near urethral orifice on right side at 10 o'clock position (Figure $1 \& 2$ ).

Mass had smooth surface with few areas of slough. On palpation it was mobile and minimally tender. Ultrasound examination of pelvis was normal. Under spinal anesthesia, urethrocystoscopy and biopsy was taken which was normal. Excision of the mass was planned. Foley's catheter was inserted and urethral opening was shifted to one side. Incision was taken medial to labia minora. The tumors got separated from periurethral tissue and was dissected from the surrounding tissue. The dissection in the paraurethral region was meticulous to reduce injury to the urethra. Complete excisional biopsy of the mass was performed. Minimal bleeding was encountered during excision. A two-layer closure was performed.

There was no postoperative complication and she gained normal lower urinary tract function after the removal of catheter 24 hours later. At 2 months follow-up, clinical examination showed normal vaginal anatomy. Patient is on follow up and is free of recurrence after a year. 


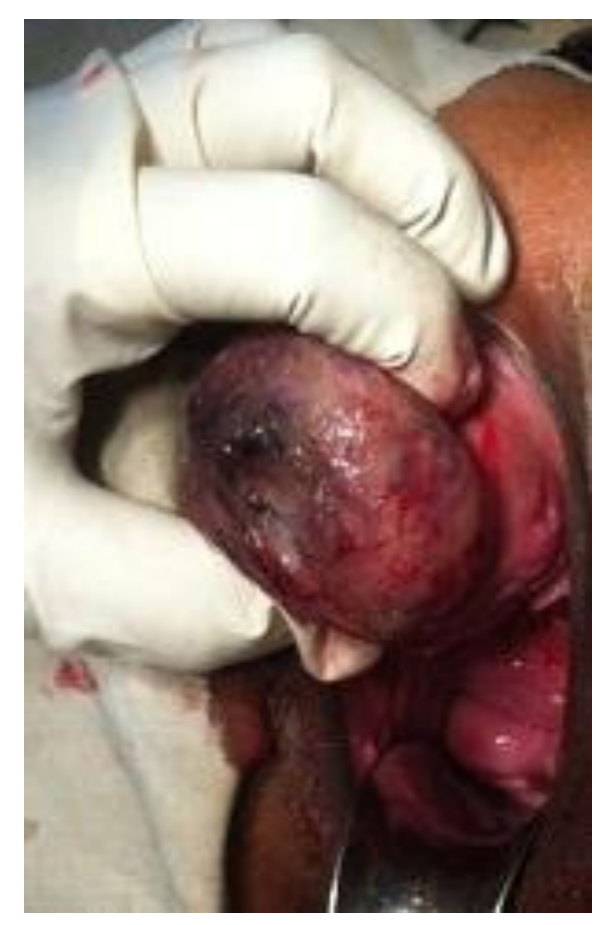

Figure 1: Soft tissue mass close to external urethral meatus.

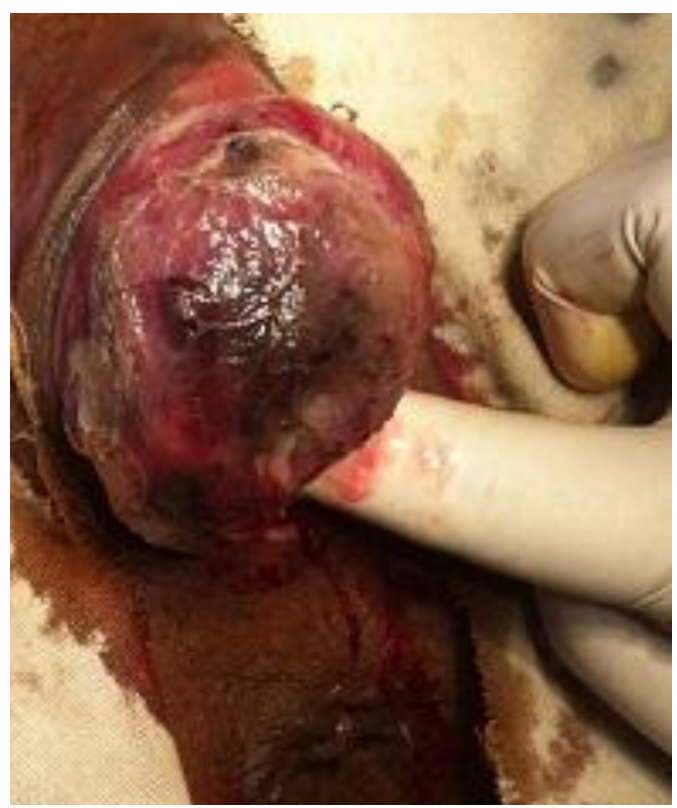

Figure 2: Soft tissue mass medial to labia minora.

The excised mass was $6 \times 7 \mathrm{~cm}$ diameter, firm in consistency, cut surface was smooth whitish, no hemorrhage and necrosis. Histopathology showed welldifferentiated spindle cells arranged in orderly intersecting fascicles. These cells had eosinophilic cytoplasm and mostly bland, uniform, cigar-shaped nuclei, resembling normal smooth muscle cells (Figure 3). Immunohistochemistry was positive for muscle markers including smooth muscle actin and desmin (Figure 4).
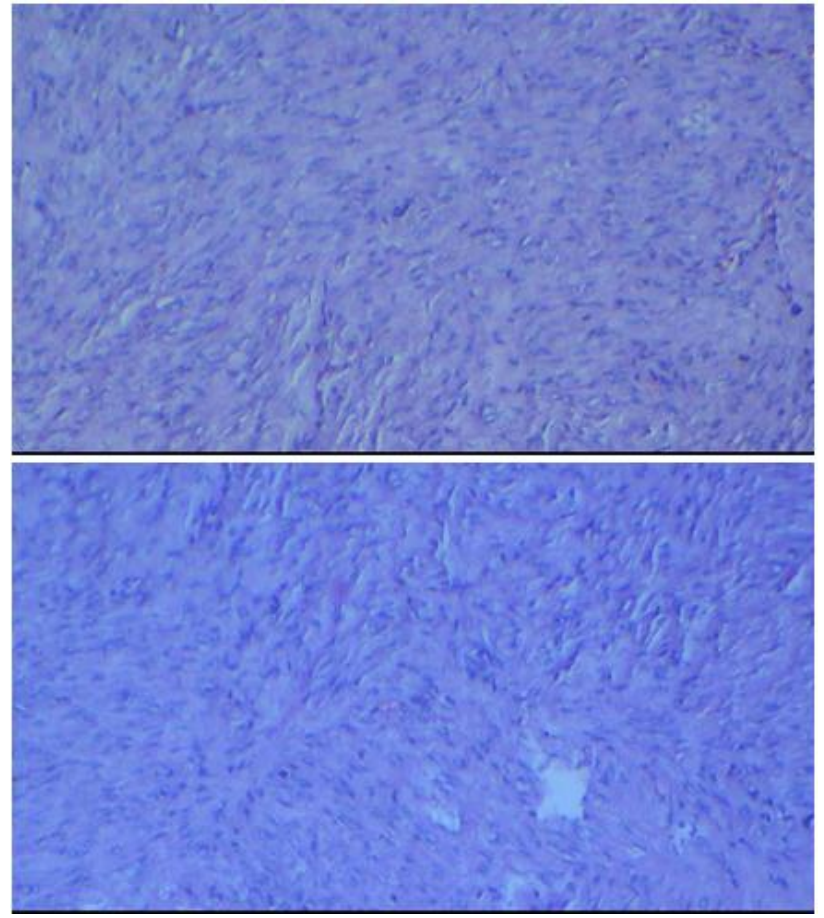

Figure 3: Spindle smooth muscle cells with eosinophilic cytoplasm and cigar-shaped blunt ended nuclei with perinuclear vacuole. (HE; magnification,

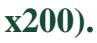

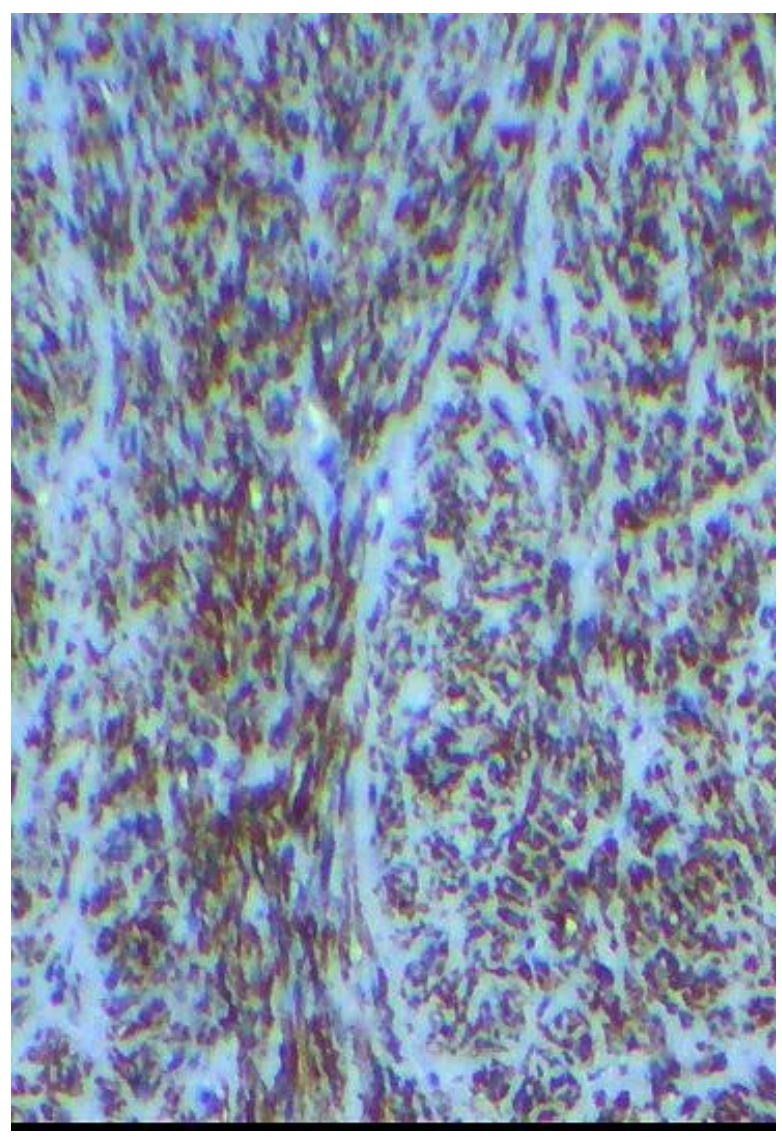

Figure 4: IHC for SMA shows diffuse positivity in tumor stroma (IHC stain, $\mathbf{4 0 0}$ ). 


\section{DISCUSSION}

Leiomyoma is a benign neoplasm commonly seen in myometrium of uterus. It is hormone sensitive tumour. It develops during hormonally active reproductive years and regresses after menopause. ${ }^{1}$ It originates from smooth muscle cells. It has been hypothesized that origin of leiomyoma is from smooth muscle cells of myometrium due to somatic mutation. There is progressive loss of growth regulation. ${ }^{4}$ In previous literature numerous extrauterine sites of leiomyoma have been described. ${ }^{2}$ There are few reports of paraurethral leiomyoma. Clinically it is difficult to know nature of these tumours.

In this case patient noticed small asymptomatic lump which grew rapidly in two weeks. Patient can present with profuse bleeding. ${ }^{5}$ Urinary symptoms are rarely described. ${ }^{6}$ Occasionally Paraurethral leiomyoma may cause urinary obstruction. ${ }^{7}$ The distinction among urethral, paraurethral, and anterior vaginal wall leiomyoma can be very difficult owing to their anatomic proximity. ${ }^{6}$

The differential diagnosis includes cystocele, urethrocele, Gartner's duct cyst, urethral diverticula, vaginal cyst, Bartholin gland cyst and vaginal malignancy. ${ }^{8}$

Transabdominal and or transvaginal ultrasonography and MRI are helpful in establishing the morphology and relationship with adjacent anatomic structures although these tests are not mandatory pre-operatively. ${ }^{9,10}$

Surgical enucleation is the treatment of choice via vaginal approach. $^{11}$ In our case the mass was superficial and easily accessible hence surgery was done with minimal morbidity. However large giant masses greater than $10 \mathrm{cms}$ have been removed transvaginally and transperitoneally. ${ }^{12}$ Preoperative embolization of a large vaginal leiomyoma to reduce intra-operative blood loss has been described. The procedure is indicated in large hyper-vascularized tumours presenting with haemorrhage. ${ }^{13}$ Though benign and slow growing vaginal leiomyoma may occasionally recur. Hence patient should be followed up for recurrence. ${ }^{14}$

Slides advocate the use of immunohistochemistry (IHC) to establish the exact diagnosis. Immunohistochemistry (IHC) for Smooth Muscle Actin (SMA) showed diffuse intense positivity in vascular wall and intervascular stroma confirming their smooth muscle nature (Figure 3 and 4). ${ }^{6}$ Patient is on follow up and is free of recurrence after a year.

\section{CONCLUSION}

Leiomyomas in extrauterine sites present a diagnostic challenge due to their rarity. Perineum, vulva, ovaries, urinary bladder, and urethra can be some of sites for these tumours. Ultrasonography might be of help in establishing the diagnosis. Leiomyomas are treated with conservative surgery. After the surgery long-term follow up is advised. To conclude, this rare case of vulval leiomyoma is reported for its rarity in literature and to bring the awareness of vaginal periurethral leiomyomas.

Funding: No funding sources

Conflict of interest: None declared

Ethical approval: Not required

\section{REFERENCES}

1. Leon Speroff, Marc A. Fritz. Leiomyomas. In: Leon Speroff, Marc A. Fritz, eds. Clinical Gynecologic Endocrinology and Infertility. 8th ed. Philadelphia: Lippincott, Williams and Wilkins; 2011: 148-480.

2. Fasih N, Prasad Shanbhogue AK, Macdonald DB, Fraser-Hill MA, Papadatos D, Kielar AZ, et al. Leiomyomas beyond the uterus: unusual locations, rare manifestations. Radiographics. 2008 NovDec;28(7):1931-48.

3. Young SB, Rose PG, Reuter KL. Vaginal fibromyomata: two cases with pre-operative assessment, resection and reconstruction. Obstet Gynaecol. 1991;78:992-4.

4. Xiaoping Luo, Nasser Chegini. The expression and potential regulatory function of microRNAs in the pathogenesis of leiomyoma. Semin Reprod Med. 2008 Nov;26(6):500-14.

5. Chong KM, Chuang J, Tsai YL, Hwang JL. A rapidly growing paraurethral myoma with profuse bleeding from a mucosal vessel: report of a case. Gynaecol Obstet Invest. 2006;61(2):87-9.

6. Perugia G1, Ciccariello M, Pirolli F, Chinazzi A, Teodonio S, Borgoni G, et al. Paraurethral leiomyoma. Urology. 2012 Apr;79(4):e51-2.

7. Bruschini H, Truzzi JC, Simonetti R, Mesquita R, Delcelo R, Szenfeld J, et al. Paraurethral leiomyoma in a female causing urinary obstruction. Int Urogynaecol J Pelvic Floor Dysfunct. 2006 May;17(3):286-9.

8. Pushkar' DIu, Anisimov AV. Paraurethral cyst and/or urethral diverticulum--differential diagnosis. Urologiia. 2007 Jul-Aug;(4):49-54.

9. Michele Scialpi, Giuseppe Benagiano, Sara Frati, Irene Piscioli, Francesco Barberini. Magnetic resonance imaging features of myxoid leiomyoma of the vagina: a case report. Indian J Radiol Imaging. 2009 Aug;19(3):238-41.

10. Hubert KC, Remer EM, Rackley RR, Goldman HB. Clinical and magnetic resonance imaging characteristics of vaginal and paraurethralleiomyomas: can they be diagnosed before surgery? BJU Int. 2010 Jun;105(12):1686-8.

11. Young SB, Rose PG, Reuter KL. Vaginal fibromyomata: two cases with pre-operative assessment, resection and reconstruction. Obstet Gynaecol. 1991; 78:992-4

12. Kuramoto T, Nishizawa S, Mori T, Iba A, Fuji R, Nanpou Y, et al. Giant paraurethral leiomyoma in the female: a case report. Hinyokika Kiyo. 2008 Oct;54(10):677-80. 
13. Bapuraj JR, Ojili V, Singh SK, Prasad GR, Khandelwal N, Suri S. Preoperative embolization of a large vaginal leiomyoma: report of a case and review of the literature. Australas Radiol. 2006 Apr;50(2):179-82.
14. Shen YH, Yang K. Recurrent huge leiomyoma of the urethra in a female patient: a case report. Oncol Lett. 2014 Jun;7(6):1933-5.

DOI: $10.5455 / 2320-1770 . i j r \operatorname{cog} 20140983$

Cite this article as: Bijwe SA, Deshmukh AT, Tanya S.

Vaginal paraurethral leiomyoma. Int J Reprod Contracept

Obstet Gynecol 2014;3:860-3. 